\title{
Insulin Resistance among Adults with Type 1 Diabetes Mellitus at the Philippine General Hospital
}

Jerome R Barrera ${ }^{1 *}$, Cecilia A Jimeno ${ }^{2}$ and Elizabeth Paz-Pacheco ${ }^{2}$

${ }^{1}$ Department of Internal Medicine, Zamboanga City Medical Center, Philippines

${ }^{2}$ Section of Endocrinology, Diabetes and Metabolism, Department of Medicine, University of the Philippines-Philippine General Hospital, Philippines

\begin{abstract}
Background: Insulin resistance has been proven to increase the risks for cardiovascular complications in type 2 diabetes mellitus. Recently, insulin resistance has also been shown to play a bigger role in the natural history of type 1 diabetes mellitus (T1DM) disease process than is commonly recognized. Limitations and difficulties in assessing insulin resistance in patients with T1DM have been addressed by the creation of clinical scoring known as estimated glucose disposal rate (eGDR). Given the clear association of insulin resistance and cardiovascular complications in diabetic patients, detecting the prevalence of insulin resistance in T1DM population, will probably clarify the welldocumented gaps in the management of this type of diabetes.
\end{abstract}

Objectives: The main objective of this study is to determine the prevalence of insulin resistance among Filipino adults with established type 1 diabetes mellitus at the Philippine General Hospital. The secondary objective is to describe the clinical features of type 1 diabetic patients with insulin resistance compared to patients without insulin resistance.

Study Design and methods: This cross-sectional analytic study recruited 104 adult subjects, 19 years old and above, with established type 1 diabetes mellitus in Philippine General Hospital. Mixed meal stimulated C-peptide level was done to confirm the diagnosis of type 1 diabetes mellitus. The main outcome measure, insulin resistance, was determined using the validated clinical scoring, Estimated Glucose Disposal Rate (eGDR) with the following formula: eGDR=24.31 $-(12.22 \times$ Waist-to-hip ratio $)-(3.29 \times 1$ if with hypertension or on anti-hypertensive or $x$ 0 if no hypertension $)-(0.57 \times \mathrm{HbA} 1 \mathrm{c})$. Patients with eGDR of $\leq 7.5 \mathrm{mg} / \mathrm{kg} / \mathrm{min}$ were considered to have insulin resistance.

Results: The prevalence rate of insulin resistance was found to be $53 \%$ among adults with established type 1 diabetes mellitus. T1DM patients with insulin resistance were significantly older (mean=29.49 \pm 8.14 yr vs $25.63 \pm$ $6.32 \mathrm{yr}, p=0.008$ ), had higher waist-to-hip ratio (mean $=0.95 \pm 0.03$ vs $0.92 \pm 0.04, p=0.000$ ), had higher systolic and diastolic blood pressure (mean=111.1 \pm 13.39 vs $105.76 \pm 10.83, p=0.028$; mean=71.82 \pm 7.76 vs $68.98 \pm 6.55$, $p=0.048$, respectively), and had poorer glycemic control (mean HbA1c $=8.31 \pm 1.73$ vs $7.67 \pm 0.90, p=0.017$ ) compare to those T1DM without insulin resistance. There were also more T1DM with insulin resistance among subjects with duration of illness of more than 5 years $(59.2 \%$ vs $40.8 \%, p=0.033)$, and among those who were either overweight or obese $(52.6 \%$ vs $47.4 \%$ and $76.2 \%$ vs $23.8 \%, p=0.023$, respectively). T1DM with insulin resistance group had higher insulin requirement per day than those without insulin resistance but the difference were not statistically significant $(p>0.5)$. Both groups had high prevalence of dyslipidemia and family history of diabetes mellitus.

Conclusion: The result of this study showed a high prevalence rate of insulin resistance among Filipino adults with established type 1 diabetes mellitus. Old age, high waist-to-hip ratio, hypertension, poor glycemic control, long duration of diabetes and overweight/obesity are the features more common among type 1 diabetic patients with insulin resistance than those without insulin resistance.

Keywords: Diabetes; Hypertension; Insulin resistance

\section{Introduction}

\section{Background and significance of the study}

Insulin resistance has been linked to the pathophysiology of type 2 diabetes mellitus and has been proven to increase the risks for cardiovascular complications. Recently, insulin resistance has also been shown to play a bigger role in the natural history of type 1 diabetes disease process than is commonly recognized. Although type 1 diabetes mellitus is mainly due to the immune destruction of pancreatic B-cells, evidences lately showed insulin resistance also plays a pathophysiological role in some cases [1]. As early as 1977, Ginsberg studied the association of insulin resistance and type 1 diabetes mellitus [2]. Subsequent studies [3,4] showed significant decrease in the insulinmediated glucose disposal rate among TIDM patients suggesting the presence of insulin resistance in the latter. But it was only after a decade that this association became the interest of many research studies $[5,6]$ investigating the possible mechanisms of insulin resistance in type 1 diabetes mellitus. Their results showed reduced glucose extraction in the skeletal muscle and skeletal muscle blood flow.

*Corresponding author: Jerome R Barrera, Department of Internal Medicine Chair, Research Committee-Technical Review Board, Zamboanga City Medica Center, Dr Evangelista St, Zamboanga City, Zamboanga Del Sur 7000, Philippines, Tel: +639285038663; E-mail: 0330jrom@gmail.com

Received October 04, 2013; Accepted November 20, 2013; Published November 24, 2013

Citation: Barrera JR, Jimeno CA, Paz-Pacheco E (2013) Insulin Resistance among Adults with Type 1 Diabetes Mellitus at the Philippine General Hospital. J Diabetes Metab 4: 315. doi:10.4172/2155-6156.1000315

Copyright: (c) 2013 Barrera JR, et al. This is an open-access article distributed under the terms of the Creative Commons Attribution License, which permits unrestricted use, distribution, and reproduction in any medium, provided the original author and source are credited. 
It has now been demonstrated that insulin resistance is present before diagnosis, at the time of diagnosis and years after the diagnosis of T1DM $[7,8]$. One study showed that insulin resistance can even accelerate the progression of moderate to high risk patients to the development of overt T1DM [9]. A study done in 20027 considered the following as the probable reasons of insulin resistance at the time of diagnosis: acute metabolic decompensation, increased counter regulatory hormones during puberty (e.g. growth hormone) and impaired glucose metabolism. Several studies showed, however, insulin resistance is more associated with older age [10], longer duration of diabetes [10], greater adiposity [10], with family history of type 2 diabetes [11], poor glycemic control [11] and elevated lipids [10]. YkiJarvinen and Koivisto specifically noted additional $40 \%$ decreased in insulin mediated glucose uptake in long standing T1DM ( $>1$ year) than newly diagnosed T1DM $(<1 \mathrm{yr})[12]$.

Two of the major limitations in assessing insulin resistance in patients with T1DM are the low prevalence and incidence of T1DM worldwide, especially in the Asian region, and the absence of noninvasive, less labor extensive method to quantify insulin resistance in this type of diabetes. Recently, however, reports showed an increase in the incidence and prevalence of T1DM. During the last decade, the annual increase in the global incidence was estimated at 3\% [13] and the predicted increase in the coming years for Asia is $4 \%$ [14]. In the latest report of International Diabetes Federation, the increase in the incidence was steeper among countries with low prevalence of T1DM [15]. It is expected that the Southeast Asian countries will contribute the largest number $(24 \%)$ of new T1DM children below 15 years worldwide [15]. In Japan, the estimated incidence rate was $22.5 / 100,000$ and total estimate of T1DM in adults was 30,000 [16]. In the Philippines, the only published report on incidence rate was reported in 1998, estimated at 0.41 cases $/ 100,000$ children aged $0-14$ years [17]

Another problem is how to quantify insulin resistance in T1DM. Homeostasis model and other validated tools for measuring insulin resistance in type $2 \mathrm{DM}$ are not applicable in T1DM, owing to the inability of the patients to synthesize insulin [18]. In addition, more invasive and costly techniques, such as euglycemic-hyperglycemic clamps, are not typically suitable for large-scale population studies $[19,20]$. Currently, the estimated glucose disposal rate (eGDR), a method based on clinical parameters that include hypertension, glycosylated hemoglobin (HbAlc), and waist-to-hip ratio (WHR), has been validated using the ideal euglycemic-hyperglycemic clamps, to determine insulin resistance specifically in T1DM [11]. The eGDR is computed using the formula: eGDR $=24.31-12.22$ (WHR) -3.29 (HTN) - $0.57(\mathrm{HbA} 1 \mathrm{c})$, where $\mathrm{WHR}=$ waist to hip ratio, $\mathrm{HTN}=$ presence or absence of hypertension (1 or 0 ) and HbAlc in \% [11]. To date eGDR has been used in several studies as a marker for insulin resistance in T1DM. Using eGDR, the prevalence of insulin resistance in T1DM was shown to be $31.9 \%$ [21] to $48 \%$ [22]. In a study done on 91 immunemediated T1DM with at least 6 months duration of disease, eGDR was $100 \%$ sensitive and $85.2 \%$ specific for metabolic syndrome and insulin resistance diagnosis [21]. Pambianco et al. [10] and Kilpatrick et al. [1] used eGDR as insulin resistance marker, and determined its association with micro- and macro-vascular complications adult subjects with long standing ( $>1 \mathrm{yr}$ ) childhood-onset T1DM. Araszkiewicz et al. [21] on the other hand, used eGDR in determining factors associated with insulin resistance in long standing adult T1DM. The provided cut-off of $7.5 \mathrm{mg} / \mathrm{kg} / \mathrm{min}$ for eGDR was able to detect insulin resistance in $48 \%$ of 81 subjects.

Currently, there are limited studies concerning T1DM in the
Philippines and specifically, there are no local studies on the prevalence of insulin resistance in T1DM patients. Given the clear association of insulin resistance and cardiovascular complications in both diabetic and non-diabetic patients, detecting the prevalence of insulin resistance in T1DM patients, will probably clarify the well-documented gaps in the management of this type of diabetes.

\section{Objectives}

1. To determine the prevalence of insulin resistance among Filipino adults with type 1 diabetes mellitus in the Philippine General Hospital.

2. To describe clinical features of type 1 diabetic patients with insulin resistance compared to those without insulin resistance.

\section{Methodology}

\section{Study design}

Cross Sectional Analytic Study

\section{Population}

\section{Inclusion criteria:}

a. All Filipino adult patients (19 years old and above) diagnosed with type 1 diabetes mellitus for at least 1year seen at the Philippine General Hospital

i. Clinical diagnosis of diabetes mellitus based on ADA criteria [23]

ii. Low Mixed meal c-peptide level [24]

a. 1-5 year- disease duration $<0.5 \mathrm{nmol} / \mathrm{L}$

b. $>5$ year-disease duration $<0.2 \mathrm{nmol} / \mathrm{L}$

b. Patients who agreed to participate in the study and have signed the informed consent form

Exclusion criteria:

c. Pregnant

d. $\mathrm{HbA1}>11.4 \%[25]$

e. Anemia

f. Chronic Kidney Disease Stage III-V [26]

g. On insulin-sensitizing agents for the past 3 months

h. Myocardial infarction within the past 3 months [27]

i. Stroke within 3 months [28]

j. Diseases of exocrine pancreas (e.g. pancreatitis, trauma, infection, pancreatectomy and pancreatic carcinoma) [23]

k. Endocrinopathies (acromegaly, cushing's syndrome, glucanoma, pheochromocytoma, hyperthyroidism, somatostatinoma, aldosteronoma) [23]

1. On following medications (pentamidine, nicotinic acid, glucocorticoids, thyroid hormone, diazoxide, B- adrenergic agonists, thiazide, dilantin and interferon) [23]

m. Genetic syndromes associated with diabetes (Down syndrome, Klinefelter syndrome and turner syndrome) [23].

\section{Sample size}

This study included 104 Filipino adults with established type 
1 diabetes mellitus. The sample size was computed to estimate the prevalence rate of insulin resistance among T1DM adults at $32 \%$ with a maximum tolerable error of $7 \%$ and confidence level of $95 \%$.

\section{Study procedures}

All adult patients clinically diagnosed as type 1 diabetes mellitus at the in-patient or out-patient departments, by the consultants, fellows and residents-in training of Department of Pediatrics, Family Medicine and Internal Medicine, and by the Consultants and Fellowsin training of Section of Endocrinology, Diabetes and Metabolism of University of the Philippines-Philippine General Hospital were recruited to participate in this study. All subjects were given consent forms that describe the significance and the objectives of the study, the data collection and laboratory tests to be done, as well as the possible adverse effects from the tests. The principal investigator took informed written consent.

The well-accepted and clinically validated mixed-meal stimulated c-peptide was used to confirm the diagnosis of T1DM [24]. Subjects on NPH took their usual dose of insulin on the evening before the test. Subjects on Insulin glargine or detimir took their usual injection the evening before and/or on the morning of the test, as per their normal routine. Usual doses of rapid-acting insulin were used until midnight before the test. Usual doses of NPH were not given on the morning of the test. The test was conducted with fasting baseline glucose $70-$ $180 \mathrm{mg} / \mathrm{dl}$ to avoid the effect of hypoglycemia and hyperglycemia on B-cell function [24]. A commercial mixed liquid meal (Ensure balanced complete meal 250 Kilocalories per $237 \mathrm{~mL}$ ) was ingested over 5 minutes, and stimulated c-peptide was measured 90 min after oral ingestion. Levels as described above were used to confirm the absence of pancreatic reserve in T1DM patients. Only those patients with c-peptides below the set cut points were included in the study.

A commercial radioimmunoassay kit was used for c-peptide determination.

\section{Determination of clinical outcomes and variables}

The following data were collected with a standardized questionnaire: age, sex, smoking history, and family history of diabetes mellitus, date and age of diagnosis, duration of illness and history of ketoacidosis. Other comorbidities such as hypertension, dyslipidemia, cardiovascular diseases and autoimmune diseases were also noted. Non-protocol medications such as antihypertensives, statins, oral hypoglycemic agents and others were also recorded.

Weight in kilograms $(\mathrm{Kg})$ and height in meters were measured using standard scale. Body mass index was calculated as weight in $\mathrm{Kg}$ divided by height in meters squared. Waist and hip circumferences were measured using non-flexible tape measure and recorded to the nearest centimeter. The subjects were in upright position and in expiratory phase with the iliac crest and the greater trochanter used as reference points, respectively. Waist-to-hip ratio was also computed as waist circumference divided by hip circumference. Blood pressure was measured using a mercurial sphygmomanometer after 15-20 minutes rest. The average of three measurements of blood pressure was recorded.

\section{Determinations of laboratory tests}

Lipid profile was measured using the COBAS Integra 400 plus Chemistry Analyzer.

\section{Computation of insulin resistance [11]}

The insulin resistance was computed using the estimated glucose disposal rate according to the following equation: (eGDR)=24.31 12.22 (waist to hip ratio) - 3.29(hypertension) - 0.57(HbA1c) where the units are milligrams per killigrams ${ }^{-1}$ per minute ${ }^{-1}$ and hypertension status is $140 / 90 \mathrm{mmHg}$ (or on medications). Blood pressures were taken three times after 5-10 min rest and the mean was used. Patients with eGDR of $\leq 7.5 \mathrm{mg} / \mathrm{kg} / \mathrm{min}$ were considered insulin resistant.

\section{Statistical analysis}

Descriptive statistics such as mean and standard deviation were presented for continuous variables. Categorical variables were expressed as frequencies and percentages.

Chi-square test was used for comparing proportions of insulin resistance between / among categorical variables (or Fisher's exact test for $2 \times 2$ tables when chi-square test assumptions were not satisfied) Independent samples t-test was used for comparing insulin-resistant and non-insulin resistant subjects in terms of variables with numerical / continuous values.

P-values less than 0.05 were considered significant. Statistical computations were performed using SPSS version 16 .

\section{Ethical considerations}

Study protocol was reviewed and approved for implementation by the PGH Expanded Hospital Research Office (EHRO).

Subjects were recruited from the Department of Internal Medicine, Department of Family Medicine and Department of Pediatric as well as from the Section of Endocrinology, Diabetes and Metabolism of the University of the Philippines-Philippine General Hospital. Subject's consent was obtained. All subjects were given consent forms that describe the significance and the objectives of the study, the data collection and laboratory tests to be done, as well as the possible adverse effects from the tests. The principal investigator read the contents of the form to the subject and obtained the consent. The subjects were given a copy of the consent form. Blood extract ions were done by the principal investigator. The left-over specimen was properly disposed and was not used for any other research purposes. Subjects were informed of the possible minimal adverse events from venipuncture like hematoma or bruise which is self-limiting and requires no further treatment. All subjects' information was kept confidential. Subjects were given P200.00 each for their transportation expenses.

Subjects were informed of the results of the laboratory tests. All subjects diagnosed with Insulin Resistance were either referred to their attending physician or were sent to the Philippine General Hospital Diabetes Clinic for further management.

This study is a recipient of the P200,000,00 Philippine Society of Endocrinology and Metabolism (PSEM) -Servier Research Grant in Diabetes for the year 2012. The investigators, who are duly members of the said society, were given one year to complete the study and to work under the monitoring guidelines set by the society. Neither PSEM nor the Servier Company holds any publication right in this study.

\section{Results}

A total of 117 subjects were screened to obtain 104 eligible subjects for the study (Figure 1). The mean age of the subjects was $27.67 \pm 7.56$ years. Half of the subjects were male. Majority of the subjects had family history of diabetes mellitus (81.7\%), had diabetic ketoacidosis (76.9\%) and were dyslipidemic (63.5\%). About $39 \%$ of the subjects were either overweight or obese, $35 \%$ were hypertensive, and $17 \%$ were current smokers. Mean duration of the disease was $10.97 \pm 6.89$ years, mean 
Citation: Barrera JR, Jimeno CA, Paz-Pacheco E (2013) Insulin Resistance among Adults with Type 1 Diabetes Mellitus at the Philippine General Hospital. J Diabetes Metab 4: 315. doi:10.4172/2155-6156.1000315

Page 4 of 6

HbA1c was $8.01 \pm 1.44$ and mean insulin dose was $1.08 \pm .47$ per $\mathrm{kg}$ body weight (Table 1).

Of the 104 subjects, 55 (53.0\%) were found to have insulin resistance (Figure 2). Among the insulin resistant patients, majority had history of diabetes mellitus in the family (83.6\%), had history of diabetic ketoacidosis (76.4\%), were hypertensive (65.5\%) and were dyslipidemic (70.9\%). About $47 \%$ were either overweight or obese and only $14.5 \%$ were current smokers. Mean duration of the disease for these patients was $12.16 \pm 6.89$ years, mean $\mathrm{HbA1c}$ was $8.31 \pm 1.73$ and mean insulin dose was $1.16 \pm 0.52$ per kg body weight (Table 1 ).

Table 2 compares the clinical and biochemical characteristics between patients with insulin resistance and without insulin resistance. T1DM patients with insulin resistance were significantly older (mean $=29.49 \pm 8.14$ yrs vs $25.63 \pm 6.32 \mathrm{yrs}, p=0.008$ ), had higher waistto-hip ratio (mean $=0.95 \pm 0.03$ vs mean $=0.92 \pm 0.04, p=0.000)$, had higher systolic and diastolic blood pressure (mean $=111.1 \pm 13.39$ vs $105.76 \pm 10.83, p=0.028$; mean $=71.82 \pm 7.76$ vs $68.9 \pm 6.55, p=0.048$, respectively), and had poorer glycemic control (mean $\mathrm{HbAlc}=8.31 \pm$

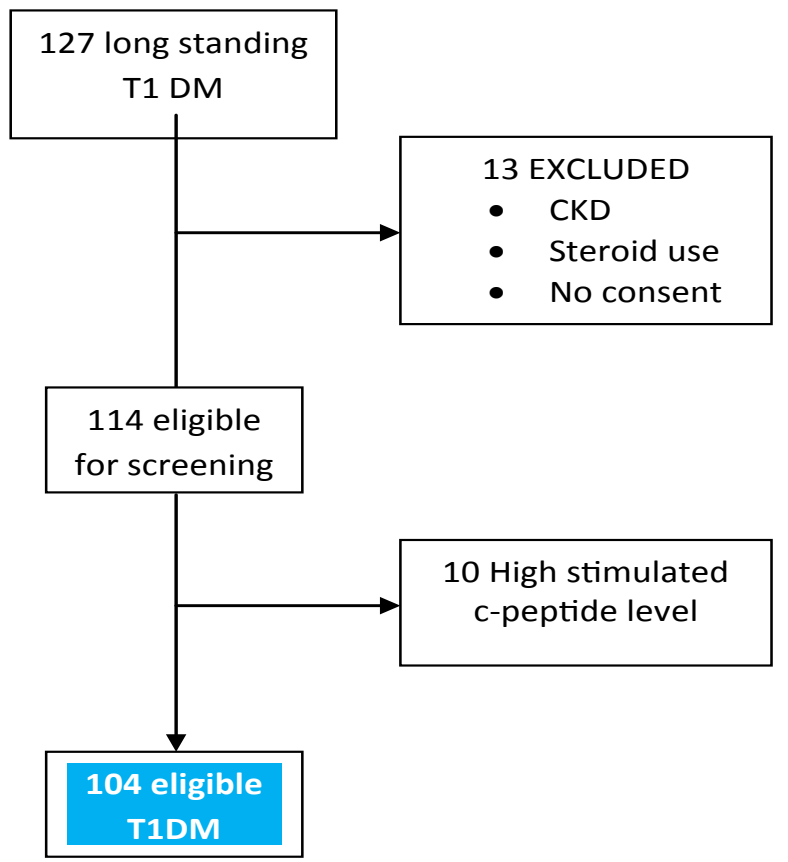

Figure 1: Study population.

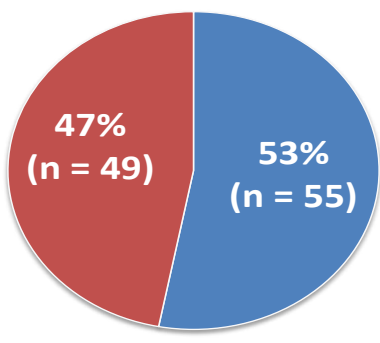

with Insulin Resistance without Insulin Resistance

Figure 2: Subjects with insulin resistance.

\begin{tabular}{|c|c|c|}
\hline $\begin{array}{l}\text { Clinical and Biochemical } \\
\text { Characteristics }\end{array}$ & $\begin{array}{c}\text { Total } \\
(n=104)\end{array}$ & $\begin{array}{l}\text { Insulin Resistant } \\
\quad(n=55)\end{array}$ \\
\hline Age in years (Mean $\pm S D)$ & $27.67 \pm 7.56$ & $29.49 \pm 8.14$ \\
\hline Male (\%) & $52(50.0)$ & $26(47.3)$ \\
\hline Duration of Illness in years (Mean \pm SD) & $10.97 \pm 6.89$ & $12.16 \pm 6.89$ \\
\hline Family history of Diabetes Mellitus (\%) & $85(81.73)$ & $46(83.6)$ \\
\hline History of Diabetic ketoacidosis & $80(76.92)$ & $42(76.4)$ \\
\hline Insulin Dose per body weight (Mean \pm SD) & $1.08 \pm .47$ & $1.16 \pm .52$ \\
\hline Current Smoker (\%) & $18(17.3)$ & $8(14.5)$ \\
\hline Body Mass Index (Mean \pm SD) & $21.71 \pm 3.66$ & $22.15 \pm 4.02$ \\
\hline Overweight or Obese (\%) & $40(38.46)$ & $26(47.3)$ \\
\hline Waist to Hip Ratio (Mean \pm SD) & $0.94 \pm .04$ & $.95 \pm .03$ \\
\hline Hypertension (\%) & $36(34.6)$ & $36(65.5)$ \\
\hline Dyslipidemia (\%) & $66(63.5)$ & $39(70.9)$ \\
\hline Systolic Blood Pressure (Mean \pm SD) & $108.59 \pm 12.49$ & $111.11 \pm 13.39$ \\
\hline Diastolic Blood Pressure (Mean \pm SD) & $70.48 \pm 7.32$ & $71.82 \pm 7.76$ \\
\hline HbA1c (Mean \pm SD) & $8.01 \pm 1.44$ & $8.31 \pm 1.73$ \\
\hline HDL (Mean \pm SD) & $55.76 \pm 17.48$ & $53.50 \pm 17.70$ \\
\hline LDL (Mean \pm SD) & $119.82 \pm 53.22$ & $117.40 \pm 61.31$ \\
\hline Triglycerides (Mean \pm SD) & $116.24 \pm 65.55$ & $118.46 \pm 66.87$ \\
\hline $\begin{array}{l}\text { Mixed Meal Stimulated C-peptide (Mean } \\
\qquad \pm S D)\end{array}$ & $0.07 \pm .11$ & $0.07 \pm .11$ \\
\hline
\end{tabular}

Table 1: Clinical and biochemical characteristics of study subjects.

\begin{tabular}{|c|c|c|c|c|c|}
\hline $\begin{array}{c}\text { Demographic and } \\
\text { Clinical } \\
\text { Characteristics }\end{array}$ & eGDR & $\mathbf{N}$ & $\begin{array}{c}\text { Mean I } \\
\text { Median }\end{array}$ & $\begin{array}{c}\text { Std. } \\
\text { Deviation }\end{array}$ & $P$-value \\
\hline \multirow{2}{*}{ Age(yr) } & With IR & 55 & 29.49 & 8.14 & $0.008^{*}$ \\
\hline & Without IR & 49 & 25.63 & 6.32 & \\
\hline \multirow{2}{*}{$\mathrm{BMI}\left(\mathrm{kg} / \mathrm{m}^{2}\right)$} & With IR & 55 & 22.15 & 4.02 & 0.193 \\
\hline & Without IR & 49 & 21.22 & 3.19 & \\
\hline \multirow{2}{*}{ Waist-to-Hip Ratio } & With IR & 55 & 0.95 & 0.03 & $0.000^{*}$ \\
\hline & Without IR & 49 & 0.92 & 0.04 & \\
\hline \multirow{2}{*}{ Mean SBP $(m m H g)$} & With IR & 55 & 111.11 & 13.39 & $0.028^{*}$ \\
\hline & Without IR & 49 & 105.76 & 10.83 & \\
\hline \multirow{2}{*}{ Mean DBP(mmHg) } & With IR & 55 & 71.82 & 7.76 & $0.048^{*}$ \\
\hline & Without IR & 49 & 68.98 & 6.55 & \\
\hline \multirow{2}{*}{ Age of Diagnosis (yr) } & With IR & 55 & 17.53 & 7.85 & 0.344 \\
\hline & Without IR & 49 & 16.03 & 8.21 & \\
\hline \multirow{2}{*}{ Duration of Illness (yr) } & With IR & 55 & 12.16 & 6.89 & 0.061 \\
\hline & Without IR & 49 & 9.63 & 6.70 & \\
\hline \multirow{2}{*}{ Insulin dose (U/Kg/Day) } & With IR & 55 & 1.16 & .52 & 0.063 \\
\hline & Without IR & 49 & .99 & .38 & \\
\hline \multirow{2}{*}{$\mathrm{HbA} 1 \mathrm{c}(\%)$} & With IR & 55 & 8.31 & 1.73 & $0.017^{*}$ \\
\hline & Without IR & 49 & 7.67 & 0.90 & \\
\hline \multirow{2}{*}{$\mathrm{HDL}(\mathrm{mg} / \mathrm{dL})$} & With IR & 55 & 53.50 & 17.70 & 0.164 \\
\hline & Without IR & 49 & 58.29 & 17.05 & \\
\hline \multirow{2}{*}{$\mathrm{LDL}(\mathrm{mg} / \mathrm{dL})$} & With IR & 55 & 117.40 & 61.31 & 0.626 \\
\hline & Without IR & 49 & 122.53 & 42.84 & \\
\hline \multirow{2}{*}{ Triglycerides(mg/dL) } & With IR & 55 & 118.46 & 66.87 & 0.717 \\
\hline & Without IR & 49 & 113.75 & 64.62 & \\
\hline \multirow{2}{*}{ C-peptide(nmol/L) } & With IR & 55 & 0.07 & 0.11 & 0.860 \\
\hline & Without IR & 49 & 0.07 & 0.11 & \\
\hline
\end{tabular}

*Significant at $\alpha=0.05$.

Table 2: Comparison of clinical and biochemical characteristics of patients with and without insulin resistance (Continuous data).

1.73 vs $7.67 \pm 0.90, p=0.017$ ) than those without insulin resistance. BMI, duration of diabetes mellitus, insulin dose per day, and triglycerides were higher among those with insulin resistance than those without while HDL and LDL levels were lower among those with insulin resistance than those without but the difference were not statistically 


\begin{tabular}{|c|c|c|c|}
\hline \multirow{2}{*}{$\begin{array}{l}\text { Demographic and } \\
\text { Clinical Characteristics }\end{array}$} & \multicolumn{2}{|c|}{ eGDR } & \multirow[t]{2}{*}{$P$ value } \\
\hline & With IR & Without IR & \\
\hline \multicolumn{4}{|l|}{ Age (years) } \\
\hline $18-39$ & $51.0 \%$ & $49.0 \%$ & 0.276 \\
\hline$>39$ & $75.0 \%$ & $25.0 \%$ & \\
\hline \multicolumn{4}{|l|}{ Sex } \\
\hline Male & $50.0 \%$ & $50.0 \%$ & 0.556 \\
\hline Female & $55.8 \%$ & $44.2 \%$ & \\
\hline \multicolumn{4}{|l|}{ Duration of Illness (years) } \\
\hline $1-5$ years & $35.7 \%$ & $64.3 \%$ & $0.033^{*}$ \\
\hline$>5$ years & $59.2 \%$ & $40.8 \%$ & \\
\hline \multicolumn{4}{|l|}{ Family history of Diabetes Mellitus } \\
\hline Yes & $54.1 \%$ & $45.9 \%$ & 0.594 \\
\hline No & $47.4 \%$ & $52.6 \%$ & \\
\hline \multicolumn{4}{|l|}{ Insulin Dose per body weight } \\
\hline$<1$ unit/kg & $50.0 \%$ & $50.0 \%$ & 0.571 \\
\hline$\geq 1 \mathrm{unit} / \mathrm{kg}$ & $55.6 \%$ & $44.4 \%$ & \\
\hline \multicolumn{4}{|l|}{ Smoking History } \\
\hline Yes & $44.4 \%$ & $55.6 \%$ & 0.430 \\
\hline No & $54.7 \%$ & $45.3 \%$ & \\
\hline \multicolumn{4}{|l|}{ Body Mass Index } \\
\hline$<18.5$ & $61.9 \%$ & $38.1 \%$ & $0.023^{*}$ \\
\hline $18.5-22.9$ & $37.2 \%$ & $62.8 \%$ & \\
\hline 23-24.9 & $52.6 \%$ & $47.4 \%$ & \\
\hline$\geq 25$ & $76.2 \%$ & $23.8 \%$ & \\
\hline \multicolumn{4}{|l|}{ Waist to Hip Ratio } \\
\hline$<0.9$ & $14.3 \%$ & $85.7 \%$ & $0.002^{*}$ \\
\hline$\geq 0.9$ & $58.9 \%$ & $41.1 \%$ & \\
\hline \multicolumn{4}{|l|}{ Hypertension } \\
\hline Yes & $100.0 \%$ & $.0 \%$ & $0.000^{*}$ \\
\hline No & $27.9 \%$ & $72.1 \%$ & \\
\hline \multicolumn{4}{|l|}{ HbA1c level (in \%) } \\
\hline$<7$ & $54.5 \%$ & $45.5 \%$ & $0.024^{*}$ \\
\hline $7-8.3$ & $39.1 \%$ & $60.9 \%$ & \\
\hline $8.4-11.4$ & $69.4 \%$ & $30.6 \%$ & \\
\hline Dyslipidemia (mg/dL) & $59.1 \%$ & $40.9 \%$ & 0.095 \\
\hline Low HDL (< 40 for males) & $57.1 \%$ & $42.9 \%$ & 0.532 \\
\hline (<50 for females) & $68.4 \%$ & $31.6 \%$ & 0.163 \\
\hline High LDL (> 130) & $46.4 \%$ & $53.6 \%$ & 0.423 \\
\hline High Triglycerides $(\geq 150)$ & $62.5 \%$ & $37.5 \%$ & 0.282 \\
\hline \multicolumn{4}{|l|}{ Stimulated C-peptide level (nmol/L) } \\
\hline$<0.2$ & $52.1 \%$ & $47.9 \%$ & 0.746 \\
\hline $0.2-0.499$ & $60.0 \%$ & $40.0 \%$ & \\
\hline
\end{tabular}

Table 3: Comparison of Clinical and Biochemical Characteristics of Patients with and without Insulin Resistance (Categorical Data).

significant $(p>0.05)$. Both groups have and low mean c-peptide level $(0.07 \pm 0.11$, respectively).

Table 3, on the other hand, showed the categorical data of the variable clinical and biochemical characteristics of T1DM with or without insulin resistance. Variables like age, sex, insulin dose per day, smoking history, dyslipidemia and c-peptide level of the T1DM patients with or without insulin resistance were all not statistically different. There was, however, higher prevalence of insulin resistance among hypertensives ( $100 \%$ vs $27.9 \%, p=0.000)$ and among patients with duration of illness of $>5$ years $(59.2 \%$ vs $35.7 \%, p=0.033)$, among those with BMI $>25$ or $<18.5$ ( $p=0.023)$, among those with WHR $>$ $0.9(58.9 \%$ vs $14.3 \%, p=.002)$, and among those with HbAlc from 8.4 to $11.4(p=0.024)$.

\section{Discussion}

The new concept of insulin resistance as the possible missing gap in our understanding of the natural history of type 1 diabetes mellitus has been gaining global acceptance among medical practitioners and researchers. Its particular association with the increase late diabetic complications, especially cardiovascular complications has triggered the development of several studies trying to connect the link between insulin resistance and type 1 diabetes mellitus.

In European countries like Finland, the country with the highest incidence/prevalence rate of T1DM in the world, insulin resistance is associated with older age [10], longer duration of diabetes [10], greater adiposity [10], with family history of type 2 diabetes [11], poor glycemic control [11] and elevated lipids. In Asian countries, the low prevalence of this disease limits the researchers to further investigate the association of insulin resistance and T1DM. In general, the prevalence rate of insulin resistance in Asians, both in diabetic and in non-diabetic population, is relatively lower compared to Caucasian counterpart. This is attributed to the lower rates of obesity in the former.

Our study looked at the prevalence of insulin resistance among Filipino adults with long standing type 1 diabetes mellitus using the clinical scoring eGDR, and described the characteristics of T1DM subjects with insulin resistance. Our results showed a higher prevalence rate of 53\% (compared to $32-48 \%$ in European countries). This could be attributed to relatively high percentage of patients with high waistto-hip ratio $(86.5 \%$ with WHR $>0.9)$, poor glycemic control $(78.8$ $\%$ with A1c > 7\%) and hypertension (34.6\%) enrolled in this study. Sixty-five percent of the overweight/obese subjects and surprisingly $100 \%$ of the hypertensive were insulin resistant. As in European studies, hypertension, older age, higher WHR, longer duration of diabetes, overweight/obese, and poor glycemic control were the features significantly more common among adultsT1DM with insulin resistance. Insulin requirement per day among T1DM subjects with insulin resistance tend to be higher than those subjects without insulin resistance, but the difference is not statistically significant. A smaller sample size of 104 in our study compare with 300 plus in the European studies probably explained the difference in the findings. In addition both groups have high number of subjects with inadequate insulin medications due to financial reasons.

High prevalence of family history of diabetes mellitus and elevated lipids present on both groups of T1DM also explained this nonsignificant difference among the said variables.

This study clearly showed the bigger role of insulin resistance in the disease course of type 1 diabetes mellitus particularly among adult population.

\section{Conclusion and Recommendations}

The result of this study showed a high prevalence rate of insulin resistance among Filipino adults with established type 1 diabetes mellitus. Old age, high waist-to-hip ratio, hypertension, poor glycemic control, long duration of diabetes and overweight/obesity are the features more common among type 1 diabetic patients with insulin resistance than those without insulin resistance.

This pilot study showed the link between insulin resistance and type 1 diabetes mellitus among Filipino adults. This study for the first time described features of Filipino type 1 diabetic adults with insulin resistance. This study is limited by the low sample size of type 1 diabetic identified in the Philippine General Hospital. Thus, future research 
Citation: Barrera JR, Jimeno CA, Paz-Pacheco E (2013) Insulin Resistance among Adults with Type 1 Diabetes Mellitus at the Philippine General Hospital. J Diabetes Metab 4: 315. doi:10.4172/2155-6156.1000315

Page 6 of 6

involving larger sample size is needed to determine which among the identified factors are associated with insulin resistance in this population. Understanding which modifiable factors prevent insulin resistance and then targeting interventions to those groups most at risk will help address the gaps in the management of type 1 diabetes mellitus.

\section{References}

1. Kilpatrick ES, Rigby AS, Atkin SL (2007) Insulin resistance, the metabolic syndrome, and complication risk in type 1 diabetes: "double diabetes" in the Diabetes Control and Complications Trial. Diabetes Care 30: 707-712.

2. Ginsberg HN (1977) Investigation of insulin sensitivity in treated subjects with ketosis-prone diabetes mellitus. Diabetes 26: 278-283.

3. DeFronzo RA, Hendler R, Simonson D (1982) Insulin resistance is a prominent feature of insulin-dependent diabetes. Diabetes 31: 795-801.

4. Del Prato S, Nosadini R, Tiengo A, Tessari P, Avogaro A, et al. (1983) Insulinmediated glucose disposal in type I diabetes: evidence for insulin resistance. $J$ Clin Endocrinol Metab 57: 904-910.

5. Baron AD, Laakso M, Brechtel G, Edelman SV (1991) Mechanism of insulin resistance in insulin-dependent diabetes mellitus: a major role for reduced skeletal muscle blood flow. J Clin Endocrinol Metab 73: 637-643.

6. Mäkimattila S, Virkamäki A, Malmström R, Utriainen T, Yki-Jarvinen H (1996) Insulin resistance in type I diabetes mellitus: a major role for reduced glucose extraction. J Clin Endocrinol Metab 81: 707-712.

7. Greenbaum CJ (2002) Insulin resistance in type 1 diabetes. Diabetes Metab Res Rev 18: 192-200.

8. Sherry N, Tsai E, Herold K (2005) Natural History of b-cell functions in Type 1 Diabetes. Diabetes 54: S32-S39.

9. Bingley PJ, Mahon JL, Gale EA; European Nicotinamide Diabetes Intervention Trial Group (2008) Insulin resistance and progression to type 1 diabetes in the European Nicotinamide Diabetes Intervention Trial (ENDIT). Diabetes Care 31: 146-150.

10. Pambianco G, Costacou T, Orchard TJ (2007) The prediction of major outcomes of Type 1 diabetes: a 12-year prospective evaluation of three separate definitions of the metabolic syndrome and their components and estimated glucose disposal rate: the Pittsburgh Epidemiology of Diabetes Complications Study experience. Diabetes Care 30: 1248-1254

11. Williams KV, Erbey JR, Becker D, Arslanian S, Orchard TJ (2000) Can clinica factors estimate insulin resistance in type 1 diabetes? Diabetes 49: 626-632.

12. Yki-Järvinen H, Koivisto VA (1986) Natural course of insulin resistance in type I diabetes. N Engl J Med 315: 224-230.

13. Onkamo P, Väänänen S, Karvonen M, Tuomilehto J (1999) Worldwide increase in incidence of Type I diabetes--the analysis of the data on published incidence trends. Diabetologia 42: 1395-1403.

14. LaPorte R, Matsushima M, Chang $Y$ (1995) Prevalence and Incidence of Insulin-Dependent Diabetes. In National Diabetes Group. Diabetes in America in Bethesda. National Institute of Health: 37-46.

15. (2010) Diabetes in the Young: a Global Perspective. Global trends in childhood type 1 diabetes. International Diabetes Federation Atlas (4thedn).
16. Kawasaki E, Matsuura N, Eguchi K (2006) Type 1 diabetes in Japan Diabetologia 49: 828-836.

17. Sy RA (2000) Prevalence of T1DM in Childhood and Adolescence in Metro Manila, Philippines. Diabetes Watch 17: 2

18. Matthews DR, Hosker JP, Rudenski AS, Naylor BA, Treacher DF, et al. (1985) Homeostasis model assessment: insulin resistance and beta-cell function from fasting plasma glucose and insulin concentrations in man. Diabetologia 28 412-419.

19. DeFronzo RA, Tobin JD, Andres R (1979) Glucose clamp technique: a method for quantifying insulin secretion and resistance. Am J Physiol 237: E214-223.

20. Chillarón JJ, Goday A, Flores-Le-Roux JA, Benaiges D, Carrera MJ, et al. (2009) Estimated glucose disposal rate in assessment of the metabolic syndrome and microvascular complications in patients with type 1 diabetes. $J$ Clin Endocrinol Metab 94: 3530-3534.

21. Araszkiewicz A, Uruska A, Zozulinska-Ziolkiewicz D, Pilacinski S, WieruszWysocka B (2010) Factors related to insulin resistance in type 1 diabetic patients treated with intensive insulin therapy from the onset of the disease. Diabetes Res Clin Pract 90: e23-24.

22. American Diabetes Association (2011) Diagnosis and Classification of diabetes Mellitus. Diabetes care 34: S62-S69.

23. Palmer JP, Fleming GA, Greenbaum CJ, Herold KC, Jansa LD, et al. (2004) $\mathrm{C}$-peptide is the appropriate outcome measure for type 1 diabetes clinical trials to preserve beta-cell function: report of an ADA workshop, 21-22 October 2001. Diabetes 53: 250-264.

24. Arslanian S, Heil BV, Kalhan SC (1993) Hepatic insulin action in adolescents with insulin-dependent diabetes mellitus: relationship with long-term glycemic control. Metabolism 42: 283-290.

25. Caravaca F, Cerezo I, Macías R, García de Vinuesa E, Martínez del Viejo C, et al. (2010) [Insulin resistance in chronic kidney disease: its clinical characteristics and prognosis significance]. Nefrologia 30: 661-668.

26. Choi KM, Lee KW, Kim SG, Kim NH, Park CG, et al. (2005) Inflammation, Insulin Resistance, and Glucose Intolerance in Acute Myocardial Infarction patients without a previous Diagnosis of Diabetes Mellitus. J Clin Endocrinol Metab 90: 175-180.

27. Vancheri F, Curcio M, Burgio A, Salvaggio S, Gruttadauria G, et al. (2005) Impaired glucose metabolism in patients with acute stroke and no previous diagnosis of diabetes mellitus. QJM 98: 871-878.

28. Kuzuya T, Nakagawa S, Satoh J, Kanazawa Y, Iwamoto Y, et al. (2002) Report of the Committee on the classification and diagnostic criteria of diabetes mellitus. Diabetes Res Clin Pract 55: 65-85. 